\title{
Production of extra-cellular slime by Staphylococcus epidermidis during stationary phase of growth: its association with adherence to implantable devices
}

\author{
R Bayston, J Rodgers
}

Abstract

A method of optimising slime production produced by Staphylococcus epidermis and its quantitative assay was developed, which gave a preliminary indication of its identity and an assessment of the correlation between slime production and adherence of the organism to implants. After inducing vigorous growth in brain heart infusion broth to stationary phase, all nutrients were removed by washing and the organisms resuspended in sterile deionised water with added magnesium. After further incubation the culture was centrifuged and the supernatant reacted with alcian blue in $50 \mathrm{mM}$ magnesium chloride/ sodium acetate solution, and the amount of bound dye was measured spectrophotometrically at $620 \mathrm{~nm}$ after its resolubilisation using sodium dodecyl sulphate. Large quantities of slime were produced by some, but not all, strains. Preliminary electrophoresis of the slime showed mobility and staining similar to that of the glycosaminoglycans. Adherence was tested by growing strains in wells of tissue culture plates and aspirating the supernatant after incubation. After fixation and staining of adherent growth the amount of bound stain was determined spectrophotometrically after its elution with ethanol.

In this series of organisms there was no correlation between the result of tests for adherence or production of extracellular slime, and no correlation between either of these and the clinical source of the organisms.

Since the introduction of surgically implantable devices Staphylococcus epidermidis has been increasingly recognised as a major cause of their colonisation. Attempts at eradicating the organisms without removal of the implant have met with only limited success, and such infections often have a profound effect on patient management.

Eighteen years ago the importance of adherence of staphylococci in hydrocephalus shunt colonisation was recognised ${ }^{1}$ and the organisms were found to produce a mucoid substance, now known as extra-cellular slime. This was later described in colonised intravenous catheters ${ }^{23}$ and has since been noted in most other colonised devices. Initially, extra-cellular slime was thought to be the means by which the cocci adhered to the silicone elastomer, but adherence has since been shown to be mediated, at least in part, by other factors. ${ }^{4}$ The importance of extracellular slime now seems to lie in its association with the failure of antimicrobial drugs to eradicate the colonising organisms, ${ }^{5}$ though there is some evidence to suggest additional effects on host defences. ${ }^{67}$ Several studies have shown that production of extra-cellular slime is more common in strains isolated from cases of implant colonisation confirmed by culture than in environmental strains or contaminants, and this has stimulated interest in laboratory tests for extra-cellular slime production as a means of assessing the clinical importance of isolates. Christensen et al have described a method of detecting extra-cellular slime production ${ }^{8}$ which has since been modified to make it quantitative. ${ }^{9}$ These tests detect adherence, though a correlation with extra-cellular slime production is implied.

Attempts have been made to characterise extra-cellular slime, and several fractions containing a variety of saccharides and amines have been examined. ${ }^{1011}$ Pure preparations of extra-cellular slime, however, have been difficult to obtain. Various media have been used to stimulate extra-cellular slime production, ${ }^{811}$ but samples of extra-cellular slime are easily contaminated by media constituents. Despite the use of various enriched or defined culture media, allusions have been made from time to time to the probable poor nutritional state of coagulase negative staphylococci colonising implants in vivo. ${ }^{12}$

In 1953 Duguid and Wilkinson found that in cultures of Aeromonas (Klebsiella) aerogenes most of the extra-cellular slime was produced after growth had stopped because of nutrient limitation. ${ }^{13}$ Similarly, Wilkinson and Stark noted the production of extra-cellular slime by washed stationary phase cells of $K$ aerogenes, ${ }^{14}$ and Bernheimer found similar results with pneumococcus. ${ }^{15}$ We therefore decided to investigate the possible production of extra-cellular slime by stationary phase 
Table 1 Sources of organisms

\begin{tabular}{|c|c|c|c|}
\hline \multicolumn{2}{|c|}{ Clinical group I } & \multicolumn{2}{|c|}{ Clinical groups $I I I, I V$} \\
\hline Number & Origin & Number & Origin \\
\hline $\begin{array}{l}241 \\
297 \\
311 \\
313 \\
314 \\
315 \\
332 \\
336 \\
363 \\
371 \\
422 \\
429 \\
441 \\
442 \\
445 \\
476 \\
544 \\
563 \\
616 \\
656 \\
708 \\
8444\end{array}$ & $\begin{array}{l}\text { CSF Shunt infection } \\
\text { CSF Shunt infection } \\
\text { CAPD peritonitis } \\
\text { CAPD peritonitis } \\
\text { CAPD peritonitis } \\
\text { CAPD peritonitis } \\
\text { CSF shunt infection } \\
\text { CAPD peritonitis } \\
\text { CSF shunt infection } \\
\text { CSF shunt infection } \\
\text { CSF shunt infection } \\
\text { Thoracovenous shunt infection } \\
\text { CAPD peritonitis } \\
\text { CAPD peritonitis } \\
\text { CAPD peritonitis } \\
\text { CSF shunt infection } \\
\text { CSF shunt infection } \\
\text { CSF shunt infection } \\
\text { CSF shunt infection } \\
\text { CSF shunt infection } \\
\text { CSF shunt infection } \\
\text { THR infection }\end{array}$ & $\begin{array}{l}242 \\
246 \\
274 \\
295 \\
298 \\
317 \\
333 \\
366 \\
374 \\
407 \\
409 \\
411 \\
412 \\
413 \\
414 \\
415 \\
416 \\
423 \\
443 \\
444\end{array}$ & $\begin{array}{l}\text { Blood culture contaminant } \\
\text { CSF shunt contaminant } \\
\text { CSF shunt contaminant } \\
\text { Skin pre-op shunt } \\
\text { CSF shunt contaminant } \\
\text { Nose, CAPD monitoring } \\
\text { Skin pre-op shunt } \\
\text { Scalp pre-cleaning } \\
\text { CSF Shunt contaminant } \\
\text { Groin, CAPD monitoring } \\
\text { Hand, CAPD monitoring } \\
\text { Nose, CAPD monitoring } \\
\text { Nose, CAPD monitoring } \\
\text { Nose, CAPD monitoring } \\
\text { Nose, CAPD monitoring } \\
\text { Umbilicus, CAPD monitoring } \\
\text { Umbilicus, CAPD monitoring } \\
\text { CSF shunt contaminant } \\
\text { Axilla, CAPD monitoring } \\
\text { Axilla, CAPD monitoring }\end{array}$ \\
\hline $\begin{array}{l}\text { Controls } \\
\text { F10 } \\
\text { F11 } \\
\text { F19 } \\
\text { F20 }\end{array}$ & $\begin{array}{l}\text { Christensen's control RP12 } \\
\text { Internal control, CSF shunt infection } \\
\text { Christensen's control SP2 } \\
\text { Christensen's control RP2A }\end{array}$ & & \\
\hline
\end{tabular}

CSF: Cerebrospinal fluid.

CAPD: Continuous ambulatory peritoneal dialysis.

THR: Total hip replacement. which were "positive", and F19, a "negative" isolate), and an internal control, F11, which had been isolated from a hydrocephalus shunt infection and whose characteristics were well known. F10, F19, and F20 were ATCC 35983, ATCC 39582, and ATCC 35984, respectively.

\section{ADHERENCE TEST}

This was based on Christensen's spectrophotometric method with some modifications. ${ }^{9}$ Briefly, the organisms were inoculated into tryptone soya broth (TSB, Oxoid) and incubated at $37^{\circ} \mathrm{C}$ for 18 hours. Aliquots of $20 \mu \mathrm{l}$ were then added to each of three wells of a sterile enzyme linked immunosorbent assay (ELISA) plate (Sterilin UK) and $200 \mu$ l of fresh sterile TSB were added. The plate was covered and incubated at $37^{\circ} \mathrm{C}$ for a further 18 hours, after which the TSB was aspirated by gentle suction. Each well was washed three times in phosphate buffered saline, and buffered glutaraldehyde was added as a fixative. After 20 minutes at room temperature this was aspirated and 200 $\mu$ l of crystal violet (GURR) as used in Gram's stain were added. After five minutes this was shaken out and the tray washed under running tap water to remove free stain. The tray was then dried for two hours at $37^{\circ} \mathrm{C}$. To each well were then added $200 \mu \mathrm{l}$ of industrial methylated spirit, and after 10 minutes the contents were mixed, $100 \mu \mathrm{l}$ transferred to a cuvette, diluted with $1 \mathrm{ml}$ of water, and the $\mathrm{A}^{1 \mathrm{~cm}} 570$ recorded.

\section{PRODUCTION OF EXTRA-CELLULAR SLIME}

Two to three colonies of each organism were inoculated into $15 \mathrm{ml}$ of brain heart infusion (Oxoid) and vortexed, after which they were incubated at $37^{\circ} \mathrm{C}$ on an orbital shaker for 18 20 hours. They were then centrifuged and

Strains of $S$ epidermidis, identified by API Staph (Biomérieux UK) and from known clinical sources (table 1) were stored at $-70^{\circ} \mathrm{C}$. The organisms were classified for other purposes into clinical groups. Groups II and V were not relevant to this study. Group I comprised those organisms which, on clear clinical and microbiological grounds, were causing an infection involving an implant. In this group there were 12 hydrocephalus shunt infections, eight cases of peritonitis in continuous ambulatory peritoneal dialysis (CAPD), one infected thoracovenous shunt for chylothorax, and one infected total hip replacement, a total of 22 strains. Group III comprised strains isolated as contaminants from removed implants where the clinical findings, serological findings if available, and the circumstances of testing and isolation clearly contraindicated implant colonisation. Group IV contained isolates from skin or mucous membranes obtained during projects involving monitoring of skin flora in patients undergoing hydrocephalus shunt surgery or CAPD. There were six strains in group III and 14 in group IV, and the two groups were combined. Controls consisted of three strains kindly donated by Dr Gordon Christensen (Memphis, Tennessee) (F10 and F20, both of
Figure 1 Scattergram of extra-cellular slime (slime) production, expressed as percentage of the reading given by the standard $25 \mathrm{mg} / \mathrm{l}$ chondroitin sulphate; and adherence, expressed as absorbance at a wavelength of $590 \mathrm{~nm} . \mathbf{0}=$ clinical group $I ; \square=$ clinical groups $I I I$ and IV.

Kendall's rank correlation test showed that there was no correlation between extra-cellular slime production and adherence $(r=0.0074)$ 
washed twice in sterile deionised water, following which they were resuspended in $10 \mathrm{ml}$ of sterile deionised water containing $20 \mathrm{mg} / 1$ magnesium chloride. After vortexing, $200 \mu \mathrm{l}$ were withdrawn and the $A^{1 \mathrm{~cm}}{ }_{490}$ recorded. The suspensions were then incubated statically at $37^{\circ} \mathrm{C}$ for $18-20$ hours. They were then centrifuged at $2800 \mathrm{rpm}$ at $4^{\circ} \mathrm{C}$ for 30 minutes and the supernatant retained.

\section{EXTRA-CELLULAR SLIME ASSAY}

The method is based on that of Whiteman. ${ }^{16}$ All strains were tested in duplicate. Alcian blue (ICI Ltd) was dissolved in sodium acetate/magnesium chloride solution, $\mathrm{pH} 5 \cdot 8$, containing $50 \mathrm{mM}$ of each, to give a dye concentration of $50 \mathrm{mg} / 100 \mathrm{ml}$.

One millilitre of supernatant, prepared as above, was mixed with $4 \mathrm{ml}$ of alcian blue solution and left to stand at room temperature for one hour. After centrifugation at $2800 \mathrm{rpm}$ at $+4^{\circ} \mathrm{C}$ for 20 minutes the supernatant was gently aspirated by suction and replaced by 4 $\mathrm{ml}$ of absolute ethanol. After gentle mixing this was again centrifuged as above and the supernatant gently aspirated and discarded, being replaced by $4 \mathrm{ml}$ of sodium dodecyl sulphate $(100 \mathrm{~g} / 1$ in $50 \mathrm{mM}$ sodium accetate, $\mathrm{pH} 5 \cdot 8$ ). The mixture was vortexed to dissolve the precipitate and the $\mathrm{A}^{1 \mathrm{~cm}}{ }_{620}$ was recorded. A background control in which $1 \mathrm{ml}$ of deionised water was substituted for the $1 \mathrm{ml}$ supernatant, and a standard consisting of $1 \mathrm{ml}$ of 25 $\mathrm{mg} / \mathrm{l}$ chondroitin sulphate (Sigma Chemical Co UK) was assayed, were included.

To calculate the result the background $\mathrm{A}^{1 \mathrm{~cm}}{ }_{620}$ was subtracted from all other readings, which were then divided by the $\mathrm{A}^{1 \mathrm{mc}}{ }_{490}$ reading for each strain to standardise extra-cellular slime production for bacterial cell density. The resulting figure was then expressed, as a percentage of the $A^{1 \mathrm{~cm}}{ }_{620}$ of the chondroitin sulphate standard.

Table 2 Results

\begin{tabular}{|c|c|c|c|c|c|}
\hline \multicolumn{3}{|c|}{ Clinical group I } & \multicolumn{3}{|c|}{ Clinical groups III and IV } \\
\hline Organism & Slime & Adherence & Organism & Slime & Adherence \\
\hline $\begin{array}{l}241 \\
297 \\
311 \\
313 \\
314 \\
315 \\
332 \\
336 \\
363 \\
371 \\
422 \\
429 \\
441 \\
442 \\
445 \\
476 \\
544 \\
563 \\
616 \\
656 \\
708 \\
8444\end{array}$ & $\begin{array}{c}26 \\
26 \\
38 \\
11 \\
15 \\
16 \\
32 \\
23 \\
32 \\
12 \\
73 \\
16 \\
52 \\
22 \\
10 \\
2 \\
0.9 \\
18 \\
29 \\
53 \\
21 \\
41\end{array}$ & $\begin{array}{l}0.305 \\
0.502 \\
0.029 \\
0.029 \\
0.079 \\
0.062 \\
0.246 \\
0.024 \\
0.412 \\
0.126 \\
0.028 \\
0.657 \\
0.031 \\
0.020 \\
0.155 \\
0.189 \\
0.203 \\
0.026 \\
0.361 \\
0.030 \\
0.087 \\
0.507\end{array}$ & $\begin{array}{l}242 \\
246 \\
274 \\
295 \\
298 \\
317 \\
333 \\
366 \\
374 \\
407 \\
409 \\
411 \\
412 \\
413 \\
414 \\
415 \\
416 \\
423 \\
443 \\
444\end{array}$ & $\begin{array}{r}9 \\
8 \\
54 \\
5 \\
32 \\
15 \\
16 \\
17 \\
30 \\
2 \\
18 \\
20 \\
25 \\
7 \\
12 \\
42 \\
35 \\
16 \\
22 \\
13\end{array}$ & $\begin{array}{l}0.147 \\
0.105 \\
0.043 \\
0.007 \\
0.270 \\
0.033 \\
0.511 \\
0.336 \\
0.354 \\
0.109 \\
0.063 \\
0.130 \\
0.114 \\
0.392 \\
0.119 \\
0.083 \\
0.062 \\
0.914 \\
0.073 \\
0.130\end{array}$ \\
\hline $\begin{array}{l}\text { Controls } \\
\text { F10 } \\
\text { F11 } \\
\text { F19 } \\
\text { F20 }\end{array}$ & $\begin{array}{l}\text { Slime } \\
41 \\
35 \\
1 \cdot 8 \\
36\end{array}$ & $\begin{array}{l}\text { Adherence } \\
0.237 \\
1.397 \\
0.020 \\
1.304\end{array}$ & & & \\
\hline
\end{tabular}

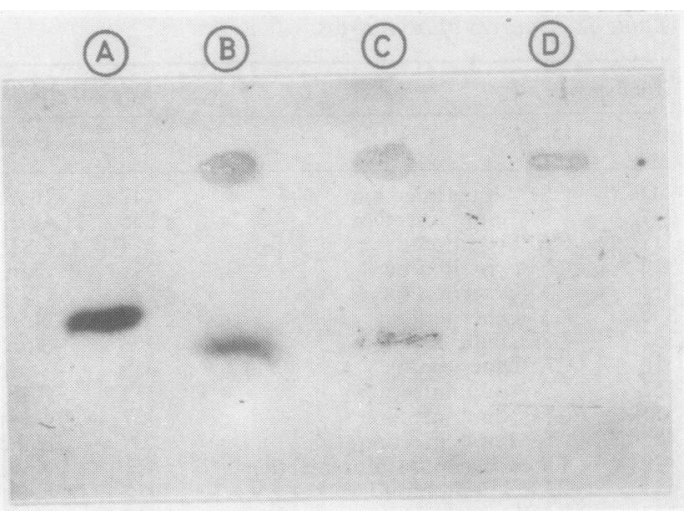

Figure 2 Sample results of electrophoresis. The results of extra-cellular slime assay and adherence of the strains are shown in Table 2. A chondroitin sulphate standard; B F11; C F422; D F19.

\section{ELECTROPHORESIS}

The method used was that described by Wessler, ${ }^{17}$ using glucose acetate and staining with alcian blue.

\section{Results}

The results of both tests are shown in table 2 . In each case they are the means of three readings. The readings for the quantitative slime assay in group I ranged from $0.9 \%$ to $73 \%$ of the standard, which contained $25 \mathrm{mg} / 1$ of chondroitin sulphate. In groups III and IV the readings ranged from $2 \%$ to $54 \%$. The three "positive" controls gave readings of $35 \%$ to $41 \%$ and the "negative" control (F19) gave a reading of $1.8 \%$.

The $\mathrm{A}^{1 \mathrm{~cm}}{ }_{590}$ readings of the adherence test for group I strains ranged from 0.020 to 0.657 , and for groups III and IV strains from 0.007 to 0.914 . Readings for the three "positive" controls ranged from 0.237 to 1.397 , and F19 gave a reading of $0 \cdot 020$. When analysed by Kendall's rank correlation test (fig 1) there was no correlation between results for the quantitative slime test and those for the adherence test $(r=$ 0.0074 ). In group I and in groups III and IV, however, there were strains which showed high readings for slime production and adherence and a few which showed low readings for both tests. Controls gave consistently reproducible readings in both tests.

The results of electrophoresis of two strains giving a high extra-cellular slime test reading are shown as examples in fig 2 , along with strain F19 and the chondroitin sulphate standard. In the two "positive" strains single bands were produced at a point near to that reached by chondroitin sulphate. In the "negative" strain no such band was produced. In all cases except the standard, alcian blue staining material also remained at the origin. Strain F422 produced a typical mobile band even though it was negative by adherence testing.

\section{Discussion}

The role of extra-cellular slime production as a virulence marker has been investigated previously. In most reported studies there are more "slime-positive" strains among those isolated from infections than among those from 
skin or environment, though these differences vary greatly, do not always reach significance, ${ }^{18-25}$ and are not found at all in some studies. ${ }^{26-28}$

In each case a version of Christensen's adherence test was used ${ }^{89}$ Some results were assessed by naked eye, while others were read using a spectrophotometer. The criteria used to determine infection also varied. There was also a tendency in some cases to assume that the terms "adherence" and "slime production" were interchangeable, though Younger et al suggested that some adherent organisms might not produce extra-cellular slime. ${ }^{25}$

Colonisation of implants seems to take place in two phases. ${ }^{329}$ In the first phase the organisms adhere to the implant, and in the second phase, which follows a few hours later, they begin to multiply and produce microcolonies and, in some cases, extra-cellular slime. The production of extra-cellular slime at this stage seems to be important as several studies have shown an apparent association between this and the failure of antimicrobial drugs to eradicate the organisms. ${ }^{519-2230}$

The clinical importance of strains which produce extra-cellular slime, but which are incapable of adhering, and vice versa, is unknown, however, and this aspect cannot be studied unless the two factors can be assayed separately. Our results suggest that this is now possible. Furthermore, the direct quantitative assay for extra-cellular slime production should serve as a reference test with which to evaluate more rapid, perhaps indirect, tests that are more suitable for use in the clinical laboratory.

We found no correlation between clinical grouping and extra-cellular slime production or adherence, or between the two factors themselves, but the strains did fall into four groups: those showing poor adherence and little or no extra-cellular slime production; those showing poor adherence and producing large amounts of extra-cellular slime; those showing strong adherence and poor extra-cellular slime production; and those able to adhere moderately well and to produce moderate amounts of extra-cellular slime. The clinical implications of these results are currently being studied, but it is possible that strains such as 423 or 544 that adhere well but are poor extracellular slime producers might cause implant colonisation which is amenable to antimicrobial treatment, while those such as 422 or 656 , though producing large amounts of extra-cellular slime, might fail to adhere to implants, leaving those strains such as 241,363 , and 8444 as the most important clinically. The results of such tests might have a major impact on the management of implant colonisation, allowing the decision to attempt eradication without removing the device, or its converse, to be made more rationally.

As extra-cellular slime can be produced in a system which is not medium dependent and in which no other nutrients are needed, purification and characterisation of extra-cellular slime is facilitated. The crude substance was found to be mainly carbohydrate by Ludwicka et $a l,{ }^{10}$ who also showed the presence of uronic acids among the hydrolysis products. Our original demonstration of extra-cellular slime production in vivo was done with alcian blue, ${ }^{1}$ and this dye has also been used by Christensen $e t$ al. ${ }^{31}$ Alcian blue, a solubilised copper phthalocyanine, bears cationic groups which react with polyanions ${ }^{32}$ that make it ideal for differential demonstration of glycosaminoglycans. ${ }^{33}$ The extra-cellular slime produced in the system reported here seems to be similar to the glycosaminoglycans (GAG). Electrophoresis shows that there are probably two substances present which react to alcian blue, one of which is produced by all strains tested and which is immobile, and a second which has a mobility similar to, but not identical with, that of chondroitin sulphate. If the proposed identity of extra-cellular slime as a GAG is confirmed this may explain some of the biological behaviour of $S$ epidermidis. A direct quantitative assay has also allowed us to proceed towards such confirmation, and to begin to investigate the factors governing the production of extra-cellular slime under various conditions.

We thank Mrs S Geddes for assistance with electrophoresis and the Wade Charitable Trust for financial support. Mrs J Rodgers is supported by a project grant from the Association for Spina Bifida and Hydrocephalus.

1 Bayston R, Penny SR. Excessive production of mucoid substance by staphylococcus SIIA: A possible factor in colonisation of Holter shunts. Devel Med Child Neurol 1972;27:25-8.

2 Peters G, Locci R, Pulverer G. Microbial colonisation of prosthetic devices II. Scanning electron microscopy of naturally infected intravenous catheters. $\mathrm{Zbl} \mathrm{Bakt} \mathrm{Hyg}$ (Orig B) 1981;173:293-9.

3 Peters G, Locci R, Pulverer G. Adherence and growth of coagulase negative staphylococci on surfaces of intravenous catheters. J Infect Dis 1982;146:479-82.

4 Hogt AH, Dankert J, De Vries JA, Feijen J. Adhesion of coagulase negative staphylococci to biomaterials. J Gen Microbiol 1983;129:2959-68.

5 Sheth NK, Franson TR, Sohnle PG. Influence of bacterial adherence to intravascular catheters on in vitro antibiotic susceptibility. Lancet 1985 ;ii:1266-8.

6 Gray ED, Peters G, Verstegen M, Regelmann WE. Effect of extracellular slime substance from Staphylococcus epidermidis on the cellular immune response. Lancet 1984; 365-7.

7 Johnson GM, Regelman WE, Gram ED, Peters G, Quie P. Staphylococcal slime and host defenses: Effects on polymorphonuclear granulocytes. Zbl Bakt Hyg 1987;Suppl 16:33-44.

8 Christensen GD, Simpson WA, Bisno AL, Beachey EH. Adherence of slime-producing strains of Staphylococcus epidermidis to smooth surfaces. Infect Immun 1982;37:318-26.

9 Christensen GD, Simpson WA, Younger JJ, et al. Adherence of coagulase-negative staphylococci to plastic tissue culture plates: A quantitative model for the adherence of Staphylococci to medical devices. $J$ Clin Microbiol 1985;22:996-1006.

10 Ludwicka A, Uhlenbruck G, Peters G, Seng PN, Gray ED, Jeljaszewicz J, Pulverer G. Investigation on extracellular slime substance produced by Staphylococcus epidermidis. Slime substance produced by Staph

11 Peters G, Schumacher-Perdreau F, Jansen B, Bey M, Pulverer $G$. Biology of $S$ epidermidis extracellular slime. Zbl Bakt Hyg 1987;(Suppl 16):15-32.

12 Sheth NK, Sohnle PG, Franson TR. Coagulase negative staphylococci (CNS) and intravascular catheters. Zbl Bakt Hyg 1987;(Suppl 16):177-81.

13 Duguid JP, Wilkinson JF. The influence of cultural conditions on polysaccharide production by Aerobacter aerogenes. J Gen Microbiol 1953;9:174-89.

14 Wilkinson JF, Stark GH. The synthesis of polysaccharide by washed suspensions of Klebsiella aerogenes. Proc Roy Soc Phys 1956;25:29-35.

15 Bernheimer AW. Synthesis of type III pneumococcal polysaccharide by suspensions of resting cells. J Exp Med 1953;97:591-600.

16 Whiteman $P$. The quantitative measurement of alcian blueglycosaminaglycan complexes. Biochem J 1973;131: 343-50.

17 Wessler E. Electrophoresis of glycosaminoglycans. In: Bal- 
zacs AE, ed. Chemistry and biology of the intercellular matrix. London: Academic Press, 1970:895-901.

18 Christensen GD, Parisi JT, Bisno AL, Simpson WA, Beachey EH. Characterisation of clinically significant strains of coagulase negative staphylococci. J Clin Microbiol 1983;18:258-69.

19 Ishak MA, Groschel DHM, Mandell GL, Wenzel RP. Association of slime with pathogenicity of coagulasenegative staphylococci causing nosocomial septicaemia. J Clin Microbiol 1985;22:1025-9.

20 Davenport DS, Massanari RM, Pfaller MA, Bale MJ, Streed SA, Hierholzer WJ. Usefulness of a test for slime producSA, Hierholzer WJ. Usefulness of a test for slime production as a marker for clinically significant infections with
coagulase-negative staphylococci. $J$ Infect Dis 1986; 153:332-9.

21 Kristinsson KG, Spencer RC, Brown CB. Clinical importance of production of slime by coagulase negative staphylococci in chronic ambulatory peritoneal dialysis. J Clin Pathol 1986;39:117-8.

22 Diaz-Mitoma F, Harding GKM, Hoban DJ, Roberts RS, Low DE. Clinical significance of a test for slime production in ventriculo peritoneal shunt infections caused by coagulase-negative staphylococci. J Infect Dis 1987; 156:555-60.

23 Dunne WM, Nelson DB, Chusid MJ. Epidemiological markers of pediatric infections caused by coagulase-
negative staphylococci. Pediatr Infect Dis $J$ 1987;6: negative

24 Hall RT, Hall SL. Barnes WG, Izuegbu J, Rogolsky M, Zorbas I. Characteristics of coagulase-negative staphylococci from infants with bacteremia. Pediatr Infect Dis $J$ 1987;6:377-83.
25 Younger JJ, Christensen GD, Bartley DL, Simmons JLH, Barrett FF. Coagulase negative staphylococci isolated from cerebrospinal fluid shunts: Importance of slime production, species identification and shunt removal to clinical outcome. J Infect Dis 1987;156:548-54.

26 Needham CA, Stempsey $W$. Incidence, adherence and antibiotic resistance of coagulase negative staphylococcus species causing human disease. Diagn Microbiol Infect Dis 1984;2:293-9.

27 Alexander W, Rimland D. Lack of correlation of slime production with pathogenicity in continuous ambulatory production with pathogenicity in continuous ambulatory negative staphylococci. Diagn Microbiol Infect Dis 1987;8: negative $215-20$.

28 Ludlam HA, Noble WC, Marples RR, Bayston R, Phillips I. The epidemiology of peritonitis caused by coagulasenegative staphylococci in continuous ambulatory peritoneal dialysis. J Med Microbiol 1989;30:167-74.

29 Hogt AH, Dankert J, Feijen J. Adhesion of coagulasenegative staphylococci onto biomaterials. Zbl Bakt Hyg 1987;(Suppl 16): 114-31.

30 Bayston R. CSF Shunt infections by coagulase-negative staphylococci. Zbl Bakt Hyg 1987;(Suppl 16):133-43.

31 Christensen GD, Baddour LM, Simpson WA. Phenotypic variation of Staphylococcus epidermidis slime production in vitro and in vivo. Infect Immun 1987;55:2870-7.

32 Scott JE, Quintarelli G, Dellovo MC. The chemical and histochemical properties of alcian blue 1 . The mechanisms of alcian blue staining. Histochemie 1964;4:73-85.

33 Scott JE, Dorling J. Differential staining of acid glycosaminoglycans (Mucopolysaccharides) by alcian blue in salt solutions. Histochemie 1965;5:221-33. 